\section{OPEN ACCESS}

Edited by:

Carlos Roncero,

University of Salamanca, Spain

Reviewed by:

Raul Felipe Palma-Alvarez,

Vall d'Hebron University Hospital, Spain

Liangsuo Ma

Virginia Commonwealth University,

United States

*Correspondence:

Virgile Clergue-Duval

virgile.clergue-duval@aphp.fr

Specialty section: This article was submitted to

Addictive Disorders,

a section of the journal

Frontiers in Psychiatry

Received: 04 May 2021 Accepted: 25 June 2021

Published: 21 July 2021

Citation:

Clergue-Duval V, Nicolas-Sacy L, Karsinti E, Zerdazi E-H, Laplanche J-L,

Brousse G, Marees AT, Derks EM, Henry P, Bellivier F, Vorspan F and Bloch V (2021) Risk and Protective

Factors of Lifetime

Cocaine-Associated Chest Pain.

Front. Psychiatry 12:704276.

doi: 10.3389/fpsyt.2021.704276

\title{
Risk and Protective Factors of Lifetime Cocaine-Associated Chest Pain
}

\begin{abstract}
Virgile Clergue-Duval ${ }^{1,2,3,4 *}$, Louise Nicolas-Sacy ${ }^{5}$, Emily Karsinti ${ }^{1,2,3,6}$, El-Hadi Zerdazi $^{2,7}$, Jean-Louis Laplanche ${ }^{2,8,9}$, Georges Brousse ${ }^{10}$, Andries T. Marees ${ }^{11}$, Eske M. Derks ${ }^{12}$, Patrick Henry 4,13 , Frank Bellivier ${ }^{1,2,3,4}$, Florence Vorspan ${ }^{1,2,3,4}$ and Vanessa Bloch ${ }^{2,3,5,9}$ on behalf of The PSYCHOCOKE investigators
\end{abstract}

\begin{abstract}
${ }^{1}$ APHP, Département de Psychiatrie et de Médecine Addictologique, Site Lariboisière Fernand-Widal, Groupe hospitalier universitaire APHP Nord - Université de Paris, Paris, France, ${ }^{2}$ Inserm UMRS-1144 Optimisation Thérapeutique en Neuropsychopharmacologie, Université de Paris, Paris, France, ${ }^{3}$ Fédération Hospitalo-Universitaire NOR-SUD Network of Research in Substance Use Disorders, Ile-de-France, France, ${ }^{4}$ Faculté de Médecine, Université de Paris, Paris, France, ${ }^{5}$ APHP, Pharmacie, Site Lariboisière Fernand-Widal, Groupe Hospitalier Universitaire APHP Nord - Université de Paris, Paris, France, ${ }^{6}$ Laboratoire ClipsyD, Université Paris Nanterre, Nanterre, France, ${ }^{7}$ APHP, Service d'addictologie, DMU IMPACT, GHU Mondor, Hôpital Emile ROUX, Limeil Brévannes, France, ${ }^{8}$ APHP, Département de Biochimie et Biologie Moléculaire, Site Lariboisière Fernand-Widal, Groupe Hospitalier Universitaire APHP Nord - Université de Paris, Paris, France, ${ }^{9}$ Faculté de Pharmacie, Université de Paris, Paris, France, ${ }^{10}$ Service de psychiatrie-addictologie, CHU de Clermont-Ferrand, Université Clermont-Auvergne, Clermont-Ferrand, France, ${ }^{11}$ Department of Economics, School of Business and Economics, VU University Amsterdam, Amsterdam, Netherlands, ${ }^{12}$ Queensland Institute of Medical Research Berghofer, Translational Neurogenomics Group, Brisbane, QLD, Australia, ${ }^{13}$ APHP, Département de Cardiologie, Site Lariboisière Fernand-Widal, Groupe Hospitalier Universitaire APHP Nord - Université de Paris, Paris, France
\end{abstract}

Introduction: Cocaine users often present with repetitive events of cocaine-associated chest pain (CACP), clinically resembling acute coronary syndromes. The aim of the study is to describe the specific risk factors for CACP.

Method: Cocaine users $(n=316)$ were recruited for a multicenter cross-sectional study. Lifetime CACP history, sociodemographic factors, and lifetime use of cocaine and other substances were assessed. Thirty single nucleotide polymorphisms (SNPS) of NOS3, ROCK2, EDN1, GUCY1A3, and ALDH2 genes, suggested by the literature on coronary spasms, were selected. The associations with CACP history were tested using the chi-square test, Student's $t$-test and logistic regression.

Results: Among the 316 subjects $[78.5 \%$ men, mean age 37.5 years, (standard-deviation \pm 8.7$)], \quad 190$ (60.1\%) were daily cocaine users and 103 (32.6\%) reported a lifetime CACP history. Among those with a lifetime CACP history, the median was 10 events per individual. In multivariate analysis, lifetime CACP history was associated with daily cocaine use [odds-ratio (OR) 3.24; 95\% confidence intervals (1.29-9.33)], rapid route of cocaine use [OR 2.33 (1.20-4.64) vs. intranasal use], and lifetime amphetamine use [daily amphetamine use: OR 2.80 (1.25-6.32) and non-daily amphetamine use: OR 2.14 (1.15-4.04) vs. never used]. Patients with lifetime opioid maintenance treatment (OMT) reported significantly less lifetime CACP history [OR $0.35(0.16-0.76)]$. None of the selected SNPs was associated with CACP history after multiple testing corrections. 
Conclusions: Clinical variables describing the intensity of stimulant use were positively associated with lifetime CACP history, while OMT was negatively associated with it. Specific harm reduction strategies can target these risk factors.

Keywords: cocaine, chest pain, acute coronary syndrome, opioid maintenance treatment, single nucleotide polymorphism, GUCY1A3, ALDH2, rs2238151

\section{INTRODUCTION}

Cocaine use is prevalent, and according to the estimates, 18 million individuals declared use of cocaine during the past year worldwide (1). Cocaine is also the fifth most consumed psychoactive substance in Europe (after alcohol, tobacco, benzodiazepine, and cannabis) and the sixth in the United States (also after opioids) $(2,3)$. In Europe, the average rate of cocaine use in the past year was $1.2 \%$ among individuals aged $15-64$ years and $2.1 \%$ among those aged 15-34 years (3). In France, in 2017, $2.8 \%$ of $18-25$-year-old and $3.4 \%$ of $26-34$-year-old individuals had used cocaine in the previous year (4).

Cocaine has a direct cardiac effect and induces several cardiovascular complications, including myocardial ischemia and infarction, acute coronary syndrome, aortic dissection, heart failure, hypertension, arrhythmias, and stroke (5-8). According to a recent study, $17.6 \%$ of patients who visited emergency departments after cocaine consumption were affected by chest pain (9). This was the third most frequent complaint after anxiety (32.2\%) and agitation or aggressive behavior (27.4\%) (9). Cocaine-associated chest pain (CACP) accounts for $1.9-6.9 \%$ of all chest pain consultations in emergency departments $(10,11)$. Among young people, these percentages are even higher, with a $25 \%$ prevalence of cocaine use among patients younger than 30 years old (10). Of note, a quarter of patients with CACP will return to the emergency department for a similar chest pain symptom during the following year (12). Indeed, lifetime CACP is reported by half of the cocaine users who received treatment in an addiction treatment center (11), and repetitive episodes are frequent (11-14). CACP is characterized by symptoms similar to those of acute coronary syndrome, including constrictive or oppressive retrosternal pain $(11,13,15)$. However, $<6 \%$ of patients with transient CACP have myocardial infarction or an underlying coronary lesion (12-17).

CACP is provoked by cocaine use through several biological processes, including increased myocardial oxygen demand (by inotropic and chronotropic effects), coronary vasoconstriction; in some cases it is associated with a prothrombotic state with increased platelet aggregation and thrombus formation $(5,6,18,19)$.

The environmental and genetic factors associated with CACP have not yet been described (7). The contribution of cocaine use pattern itself and the effect of other substance use deserve a specific analysis. Thus far, early cocaine use initiation has been associated with a higher risk of lifetime CACP history (11). A specific role of alcohol intake in the occurrence of cardiac events in subjects with cocaine use has been suggested by a pharmacodynamic interaction related to the concurrent use or addition of the two substances, thus acting as cardiovascular risk factors (20). The concomitant use of cocaine and alcohol produces cocaethylene, which has a longer half-life than cocaine and may prolong cardiac effects $(21,22)$. Tobacco smoking is also a known cardiovascular risk factor and has a significant effect on the general population. Nevertheless, in the analysis of health data regarding cocaine use in the USA, regular cocaine use was shown to increase the risk of myocardial infarction in both subjects with and without concurrent tobacco use disorder, with similar odds ratios (8). On the other hand, no study has considered the concomitant use of opioids as a risk factor for cardiovascular events in cocaine users. However, a previous analysis conducted in the same sample involving patients who used opioids before their first cocaine use, reported significantly less anxiety and tachypsychia while using cocaine than patients who had not used opioids (23), suggesting that opioid use should also be taken into account.

Concerning the hypothesis of genetic variability of CACPs, the literature identifies several genes contributing to the general pathophysiology of vasospasms $(5,6)$. These genes belong to the NOS signaling pathway, including NOS3, ROCK2, $E D N 1$, and GUCY1A3, and have been associated with coronary spasm episodes (24-28). Furthermore, several polymorphisms of $A L D H 2$, the gene coding for the enzyme metabolizing acetaldehyde, have also been shown to increase the risk of coronary spasms in East Asian populations (29). ALDH2 is also the most replicated risk gene for excessive alcohol use $(30,31)$ and alcohol-related complications (32).

The aim of the present study was to describe the clinical and genetic risk and protective factors of lifetime CACP history in a sample of cocaine users recruited in a substance use disorder care setting, with a specific focus on alcohol, tobacco, and opioid co-occurring use disorder.

\section{MATERIALS AND METHODS}

\section{Subjects and Sampling Procedure}

The subjects were cocaine users, recruited between 2012 and 2016 in nine urban out- or inpatient specialized treatment centers were they were currently treated for substance use disorders in France (NCT01569347). They were recruited if they used cocaine regardless of whether they met criteria for cocaine use disorder. As European ethnicity was not an inclusion criterion, we $a$ posteriori selected subjects with European ancestry by comparing identity by descent to the 1000 Genome database, as described in Marees et al. (33).

\section{Measure of CACP Lifetime History}

The records of lifetime CACP events were retrospectively analyzed. First, the subjects were interviewed about their 
lifetime history of chest pain using the procedure proposed by Edmondstone (34). Those who reported such a history were requested to describe the phenomenology of these events, using the sentence "show me where your pain was and tell me what it felt like." The chest pain events were rated by the investigator as plausible cardiac origin if they matched with the three Edmondstone's descriptions ("clenched fist to the center of the sternum," "flat hand to the center of the sternum," or "both flat hands drawn from the center of the chest outwards"). This method had a sensitivity of $80 \%$, a specificity of $49 \%$, a positive predictive value of $77 \%$ and a negative predictive value of $53 \%$ (34). Only pain events with both Edmondstone's phenomenology and consistent time relation with cocaine use were retained for the analysis.

The number of lifetime CACP occurrences, pain type (constrictive, oppressive, burn, or stabbing), pain location (retrosternal, laterothoracic, or dorsal), pain intensity, average time of occurrence after the beginning of cocaine use session, average duration of CACP, age at the first CACP occurrence, and history of medical consultation for any of these CACP events were also recorded.

\section{Sociodemographic Factors and Pattern of Substances Use}

Sociodemographic factors were collected at the time of inclusion. These included age, body mass index (BMI), sex, and educational attainment.

The characteristics of lifetime cocaine use and history of other substances were recorded. Lifetime cocaine use was characterized in terms of age at the first use, frequency, preferred routes of cocaine use (intranasal vs. rapid route of use, i.e., smoked and/or intravenous use), ever used cocaine through intravenous administration, and the type of cocaine (crack vs. cocaine hydrochloride) during the worst period of use. Concerning other substances, lifetime histories of use or DSMIV-TR dependence criteria (35) were recorded for tobacco, alcohol, cannabis, amphetamines, opioids, and lifetime opioid maintenance treatment (OMT) prescriptions.

\section{Genetic Factors}

\section{Single Nucleotide Polymorphisms Genotyping}

Genomic DNA was extracted from EDTA-treated peripheral blood samples and genotyped using the Illumina Infinium PsychArray24 v1.1 BeadChip, containing 571054 single nucleotide polymorphisms (SNPs).

\section{SNPs Selection and Genetic Quality Control}

A focused candidate gene approach was used. NOS3, ROCK2, $E D N 1, G U C Y 1 A 3$, and $A L D H 2$ were selected. From these five genes, we retrieved 120 genotyped SNPs from the PsychArray chip. We applied a quality control selection with the following parameters: SNP genotyping rate $\geq 0.05$, minor allele frequency $\geq 0.05$, and no significant deviation from Hardy Weinberg Equilibrium ( $p$-value $<0.001)$. In the per-individual quality control, we excluded outliers with excessive missing genotyping $(>0.05)$ and heterozygosity ( $> \pm 3 \mathrm{SD}$ ) rates (33). We finally retained 30 out of 120 SNPs (Supplementary Table $\mathbf{1}$ ).

\section{Statistical Analysis}

Associations of lifetime CACP history with clinical variables were tested with the chi-square or Student's $t$-test as appropriate, with a specific focus on cocaine use pattern itself and the effect of other substance use. Multivariate analysis of CACP history was performed using logistic regression, with a threshold for entry of $p<0.10$. Age, sex, lifetime opioid use, and alcohol dependence were added to the model to account for these population-specific factors. Sensitivity analyses according to the first OMT drug ever prescribed as well as the currently prescribed OMT were performed using logistic regression.

In the subgroup of patients with a lifetime history of CACP, the number of CACP occurrences by year of regular cocaine use ratio was calculated. We tested the univariate association between this ratio and each clinical and socio-demographic variable with quasi-Poisson regressions to select variables with a threshold for entry $(p<0.10)$ for a multivariate quasi-Poisson regression. Similarly, age, sex, frequency of cocaine use during the worst period, lifetime opioid use, and alcohol dependence were also added to the model.

For genetic analyses, the association of the SNPs that passed the quality check with (i) lifetime CACP history (chi-square test) and (ii) CACP episodes per year ratio were tested (quasi-Poisson regressions), with a correction for multiple testing using the false discovery rate (FDR) method. We then included genetic factors $(p<0.10)$ in the two previous multivariate analyses. Interaction factors $(p<0.10)$ were retained. Model predictabilities were estimated by McFadden's pseudo- $\mathrm{R}^{2}$ and compared with the likelihood-ratio test.

Epidemiological statistical analyses were performed using $\mathrm{R}$ software version 3.2. Quality control of genetic data and statistical genetic analyses were performed using PLINK 1.9.

\section{Ethics}

The study was conducted in accordance with the Declaration of Helsinki and French laws on biomedical research. Written informed consent was obtained from all participants. This study was approved by the relevant ethics committee (CPP Ile de France IV) in March 2011.

\section{RESULTS}

\section{Subjects' Characteristics}

The original sample consisted of 418 subjects. Clinical data on lifetime CACP history were available for 316 subjects; among them, 290 were identified as having European ancestry.

Among the 316 subjects, 68 were women (21.5\%) and 248 were men $(78.5 \%)$. The mean age was 37.5 years $(S D \pm 8.7)$. The median length of regular cocaine use was 5 years. The frequency of cocaine use during the worst period was daily for $60.1 \%$ of the subjects and weekly for $29.4 \%$. Crack use was described by $27.8 \%$ of the subjects, and smoked or/and intravenous cocaine use was preferred by $38.3 \%$. Lifetime alcohol and cannabis dependence were observed in 63.2 and $61.2 \%$ of the subjects, respectively. Among the 140 subjects (44.4\%) with lifetime OMT prescription, 84 were currently on methadone 
TABLE 1 | Subjects' characteristics and lifetime substances use pattern ( $n=316)$ (n, \%).

\begin{tabular}{|c|c|c|}
\hline Sex & Male & $248(78.5 \%)$ \\
\hline \multirow[t]{2}{*}{ Age (years) } & Mean (SD) & $37.47( \pm 8.65)$ \\
\hline & Minimum-Maximum & 19-65 years \\
\hline \multirow[t]{4}{*}{ Body mass index $\left(\mathrm{kg} / \mathrm{m}^{2}\right)$} & $<21.0$ & $80(26.1 \%)$ \\
\hline & 21.0-24.99 & $132(43.1 \%)$ \\
\hline & $\geq 25.0$ & $94(30.7 \%)$ \\
\hline & Missing & 10 \\
\hline \multirow[t]{3}{*}{ Academic attainment } & $<$ High school degree & $88(27.8 \%)$ \\
\hline & High school degree & 93 (29.4\%) \\
\hline & Graduate degree & 135 (42.7\%) \\
\hline \multirow{3}{*}{$\begin{array}{l}\text { Frequency of cocaine use during } \\
\text { the worst period }\end{array}$} & Daily & $190(60.1 \%)$ \\
\hline & 1-6 use by week & $78(24.7 \%)$ \\
\hline & Less than weekly & $48(15.2 \%)$ \\
\hline \multirow[t]{2}{*}{$\begin{array}{l}\text { Length of regular cocaine use } \\
\text { (year) }\end{array}$} & $\begin{array}{l}\text { Median (Minimum- } \\
\text { Maximum) }\end{array}$ & $5(1-34)$ \\
\hline & 1st quartile; 3rd quartile & $2.5 ; 11$ \\
\hline $\begin{array}{l}\text { Crack use (vs. cocaine } \\
\text { hydrochloride) }\end{array}$ & Yes & $88(27.8 \%)$ \\
\hline \multirow[t]{2}{*}{ Preferred route of cocaine use: } & $\begin{array}{l}\text { Smoked } \\
\text { or/and intravenous }\end{array}$ & $121(38.3 \%)$ \\
\hline & Intranasal (sniffed) & 195 (61.7\%) \\
\hline \multirow{2}{*}{$\begin{array}{l}\text { History of intravenous cocaine } \\
\text { use }\end{array}$} & Yes & $85(26.9 \%)$ \\
\hline & Missing & 1 \\
\hline \multirow[t]{2}{*}{ Age of cocaine first use (years) } & Mean (SD) & $23.4( \pm 7.3)$ \\
\hline & $\begin{array}{l}\text { Median (Minimum- } \\
\text { Maximum) }\end{array}$ & 21.0 years $(12-53)$ \\
\hline \multirow{4}{*}{$\begin{array}{l}\text { Opioid use and opioid } \\
\text { maintenance treatment (OMT) }\end{array}$} & Never & $103(32.7 \%)$ \\
\hline & $\begin{array}{l}\text { Opioid use } \\
\text { without OMT }\end{array}$ & $72(22.9 \%)$ \\
\hline & OMT use & $140(44.4 \%)$ \\
\hline & Missing & 1 \\
\hline \multirow{4}{*}{$\begin{array}{l}\text { Amphetamine use during the } \\
\text { worst period }\end{array}$} & Never & 124 (39.9\%) \\
\hline & Non-daily use & $131(42.1 \%)$ \\
\hline & Daily use & $56(18.0 \%)$ \\
\hline & Missing & 5 \\
\hline \multirow[t]{3}{*}{ Tobacco use } & Less than daily use & $19(6.0 \%)$ \\
\hline & Daily use & $296(94.0 \%)$ \\
\hline & Missing & 1 \\
\hline \multirow[t]{3}{*}{ Lifetime alcohol use ${ }^{\star}$} & No dependence & $114(36.8 \%)$ \\
\hline & Dependence & 196 (63.2\%) \\
\hline & Missing & 6 \\
\hline \multirow[t]{3}{*}{ Lifetime cannabis use* } & No dependence & $121(38.8 \%)$ \\
\hline & Dependence & $191(61.2 \%)$ \\
\hline & Missing & 4 \\
\hline \multirow{3}{*}{$\begin{array}{l}\text { ALDH2 rs2238151 genotype ( } N \\
=96, \text { sample restricted to } \\
\text { patients with lifetime CACP } \\
\text { history) }\end{array}$} & $\mathrm{CC}$ & 19 (19.8\%) \\
\hline & CT & $34(35.4 \%)$ \\
\hline & $\pi$ & 43 (44.8\%) \\
\hline
\end{tabular}

(Continued)
TABLE 1 | Continued

$\begin{array}{lll}\begin{array}{l}\text { ALDH2 rs2238151 genotype (N } \\ =76, \text { sample restricted to }\end{array} & 9(11.8 \%) \\ \begin{array}{l}\text { patients with lifetime CACP } \\ \text { history and European Ancestry) }\end{array} & & \\ & \text { CT } & 30(39.5 \%) \\ & \text { TT } & 37(48.7 \%)\end{array}$

*Dependence according to DSM IV -TR criteria.

(60.0\%), 37 were currently on buprenorphine (26.4\%) and 19 had ceased OMT (13.6\%). The first OMT prescription was methadone for 47 subjects (34.3\%) and buprenorphine for $90(65.7 \%)$. The characteristics of the subjects are shown in Table 1.

\section{Lifetime CACP History}

Of the 316 subjects, $103(32.6 \%)$ reported at least one episode of lifetime CACP history. Among those with a lifetime history of CACP, 86 (87.8\%) described several episodes with a median of 10 events per individual. The pain was retrosternal in $57(60.6 \%)$ and oppressive in 49 $(50.0 \%)$ subjects. Twenty-five $(24.8 \%)$ consulted a medical doctor after a CACP event. The details are presented in Table 2.

\section{Clinical Factors Associated With a Lifetime CACP History}

In the univariate analysis, subjects with a lifetime history of CACP were significantly younger (36.0 vs. 38.2 years, $p=0.034$ ). They also described a higher frequency of cocaine use $(p=0.016)$, amphetamine use $(p=0.012)$, and a preference for rapid route of cocaine use (i.e., smoked and/or intravenous use) during the worst period ( $p=0.034$ ) (Table 3 ).

In the multivariate analysis, age was not found to be an independent risk factor $(p=0.17)$. We observed an association between the lifetime history of CACP and three factors describing the severity of lifetime psychostimulant use: (i) the frequency of cocaine use [daily cocaine use: odds ratio (OR) 3.24; 95\% confidence interval (95\%CI) (1.299.33) vs. less than weekly cocaine use], (ii) the frequency of amphetamine use [daily amphetamine use: OR 2.80; 95\%CI (1.25-6.32); and non-daily amphetamine use: OR 2.14, 95\%CI (1.15-4.04) vs. no lifetime amphetamine use], and (iii) the preference for rapid route of cocaine use [OR 2.33; $95 \%$ CI (1.20-4.64) vs. intranasal cocaine use]. Conversely, receiving or having received a prescribed OMT was inversely associated with lifetime CACP history [OR 0.35; 95\%CI (0.15$0.76)$ vs. no lifetime opioid use]. Overall, the multivariate analysis model, performed for 282 subjects, was significantly different from the null model (McFadden's pseudo- $\mathrm{R}^{2}=$ $0.085, p=3.0 \times 10^{-3}$ ). In sensitivity analyses in the multivariate model, according to the OMT drug prescribed, no significant difference was observed for the first OMT drug prescribed [buprenorphine vs. methadone: OR 0.63; 95\% CI (0.25-1.64)], for the current OMT drug prescribed 
TABLE 2 | Characteristics of CACP $(n=103)$.

\begin{tabular}{|c|c|}
\hline \multicolumn{2}{|c|}{ Number of CACP occurrence } \\
\hline Median & 10 \\
\hline Minimum-Maximum & $1-40$ \\
\hline 1 & $12(12.2 \%)$ \\
\hline $2-5$ & $19(19.4 \%)$ \\
\hline $6-10$ & $36(36.7 \%)$ \\
\hline $11-20$ & $29(29.6 \%)$ \\
\hline$>20$ & $2(2.0 \%)$ \\
\hline Missing & 5 \\
\hline \multicolumn{2}{|l|}{ Pain type } \\
\hline Constrictive & $29(29.6 \%)$ \\
\hline Oppressive & $49(50.0 \%)$ \\
\hline Burn & $5(5.1 \%)$ \\
\hline Stabbing & $15(15.3 \%)$ \\
\hline Missing & 5 \\
\hline \multicolumn{2}{|l|}{ Pain location } \\
\hline Retrosternal & $57(60.6 \%)$ \\
\hline Laterothoracic & $30(31.9 \%)$ \\
\hline Dorsal & $7(7.4 \%)$ \\
\hline Missing & 9 \\
\hline \multicolumn{2}{|c|}{ Pain intensity between 1 and $10(n=101)$} \\
\hline Mean (SD) & $6.2( \pm 2.3)$ \\
\hline Median & 6.0 \\
\hline Minimum-Maximum & $1-10$ \\
\hline \multicolumn{2}{|c|}{ Average lapse of time of occurrence of CACP after cocaine use } \\
\hline$\leq 10 \min$ & $25(25.8 \%)$ \\
\hline$>10$ to $\leq 30 \mathrm{~min}$ & $19(19.6 \%)$ \\
\hline$>30 \min$ to $\leq 1 \mathrm{~h}$ & $18(18.6 \%)$ \\
\hline$>1$ to $\leq 5 h$ & $23(23.7 \%)$ \\
\hline$>5$ to $\leq 24 h$ & $10(10.3 \%)$ \\
\hline$>24$ to $<48 \mathrm{~h}$ & $2(2.1 \%)$ \\
\hline Missing & 6 \\
\hline \multicolumn{2}{|c|}{ Average duration of CACP } \\
\hline$\leq 10 \min$ & $33(34.4 \%)$ \\
\hline$>10$ to $\leq 30 \mathrm{~min}$ & $21(21.9 \%)$ \\
\hline$>30$ min to $\leq 2 \mathrm{~h}$ & $20(28.8 \%)$ \\
\hline$>2$ to $\leq 5 \mathrm{~h}$ & $14(14.6 \%)$ \\
\hline$>5$ to $\leq 24 h$ & $6(6.3 \%)$ \\
\hline$>24$ to $<48 \mathrm{~h}$ & $2(2.1 \%)$ \\
\hline Missing & 7 \\
\hline \multicolumn{2}{|c|}{ Age of first occurrence (years) $(n=94)$} \\
\hline Mean (SD) & $30.6( \pm 7.6)$ \\
\hline Median & 29.5 \\
\hline Minimum-Maximum & $16-50$ \\
\hline \multicolumn{2}{|c|}{ Medical consultation for CACP } \\
\hline Yes & $25(24.8 \%)$ \\
\hline No & $76(75.2 \%)$ \\
\hline Missing & 2 \\
\hline
\end{tabular}

[buprenorphine vs. methadone: OR 0.84; 95\% CI (0.30-2.26)], and for OMT continuation vs. OMT cessation [OR 0.50; $95 \%$ CI (0.15-1.73)].

\section{Clinical Factors Associated With a Higher CACP Occurrence per Year Ratio}

Univariate analysis was performed on 103 subjects with a lifetime $\mathrm{CACP}$ history. The younger subjects displayed a significantly higher ratio (quasi-Poisson regression: $\beta=-0.047 ; p=4.5$ $\times 10^{-3}$ ). None of the factors describing psychostimulant use intensity were associated with a higher ratio. In the multivariate analysis performed for 90 subjects, age remained an independent factor after adjustment for sex, cocaine use frequency, lifetime opioid use, and alcohol dependence [quasi-Poisson regression $\beta=-0.051 ; 95 \%$ CI $\left.(-0.085 ;-0.018), p=4.3 \times 10^{-3}\right]$. Overall, this second multivariate analysis model was significant (McFadden's pseudo- $\mathrm{R}^{2}=0.16, p<10^{-3}$ ).

\section{Genetic Association}

Of the 120 selected SNPs, 30 passed the quality control. In the univariate analysis of each individual SNP with lifetime CACP history, the two top SNPs were $r s 7658967$ and $r s 13139571$ (GUCY1A3 gene), with a $p$-value of 0.025 and 0.10 , respectively, before FDR correction (after FDR correction: 0.76 and 1.0). The inclusion of these two SNPs in the multivariate model of CACP history did not change the associations observed with cocaine, amphetamine, and opioid use (McFadden's pseudo- $\mathrm{R}^{2}$ without SNPs $=0.077$ performed in 271 subjects, McFadden's pseudo$\mathrm{R}^{2}$ with two SNPs $\left.=0.089 ; p=0.54\right)$. As the genetic analyses did not identify any significant association between the two GUCY1A3 SNPs and lifetime CACP history, we did not further adjust for ethnicity.

Similarly, we tested the association of the 30 SNPs that passed the quality check with the CACP occurrence per year ratio. The top SNP was $r s 2238151$ (ALDH2 gene) with a $p$-value of 0.017 before FDR correction (and $p=0.52$, after FDR correction). The risk genotype was CC vs. TT $[\beta=0.89$; $95 \%$ CI $(0.28-$ 1.50)]. In the quasi-Poisson regression multivariate model of the occurrence ratio performed for 83 subjects, a significant interaction was observed between $r s 2238151$ and two clinical variables: frequency of cocaine use $\left(p=9.8 \times 10^{-3}\right)$ and alcohol dependence $(p=0.026)$, as well as an interaction with age $(p=0.064)$. The stepwise regression retained the frequency of cocaine use, age, alcohol dependence, $r s 2238151$ variables, and the interaction terms (McFadden's pseudo- $\mathrm{R}^{2}=0.536 ; p<10^{-4}$ ). When restricting the quasi-Poisson regression to the 76 European subjects, the only observed significant interaction $(p=4.5 \times$ $10^{-3}$ ) was between the frequency of cocaine use and $r s 2238151$ (McFadden's pseudo- $\mathrm{R}^{2}=0.487, p<10^{-4}$ ).

\section{DISCUSSION}

A lifetime CACP history was observed in $32.6 \%$ of this sample, and $87.8 \%$ of patients describing one event had repetitive occurrences. Of note, only a quarter of the affected subjects consulted a medical doctor following a CACP event.

As a summary of the risk factors that we identified, we can state that the frequency of cocaine and amphetamine use and the preference for rapid routes of administration were associated with lifetime CACP history, in contrast to that with 
TABLE 3 | Analyses of lifetime CACP history $(n=316)$.

Cocaine-Associated Chest Pain (CACP) history

\begin{tabular}{|c|c|c|c|c|c|}
\hline \multicolumn{3}{|c|}{ Univariate analysis; $n(\%) \quad(n=316)$} & \multicolumn{3}{|c|}{ Multivariate analysis $(n=282)$} \\
\hline $\begin{array}{c}\text { CACP } \\
(n=103)\end{array}$ & $\begin{array}{l}\text { No CACP } \\
(n=213)\end{array}$ & Test $p$-value & OR & OR $95 \% \mathrm{Cl}$ & $p$-value \\
\hline
\end{tabular}

Sex

Female

Male

Age (years); Mean (SD)

Body mass index $\left(\mathrm{kg} / \mathrm{m}^{2}\right)$

$<21.0$

21.0-24.99

$\geq 25.0$

Missing

Frequency of cocaine use during the worst period

Daily

1-6 use by week

Less than weekly

\section{Crack use}

Yes

No, cocaine hydrochloride only

Preferred route of cocaine use

Smoked or/and intravenous

Intranasal (sniffed)

\section{History of intravenous cocaine use}

Yes

No

Missing

Age of cocaine first use; Mean (SD)

Length of regular cocaine use (years)

Lifetime opioid use and opioid maintenance treatment (OMT)

OMT use

Opioid use without OMT

Never

Missing

Lifetime initiation of cocaine and opioids use

Cocaine before opioid

Opioid before cocaine or at the same time

Missing

Amphetamine use during the worst period

Daily use

Non-daily use

Never use

Missing

Age of amphetamine first use; Mean (SD)

Lifetime initiation of cocaine and amphetamine use

Cocaine before amphetamine

Amphetamine before cocaine or at the same time

Missing

Number of cigarette by day;

Mean (SD)

\section{Alcohol use}

Dependence

No dependence

Missing

\begin{tabular}{|c|c|c|c|c|c|}
\hline $\begin{array}{l}25 \text { (36.8\%) } \\
78 \text { (31.5\%) }\end{array}$ & $\begin{array}{c}43(63.2 \%) \\
170(68.5 \%)\end{array}$ & $\mathrm{Chi}^{2} 0.41$ & $\begin{array}{l}1.06 \\
\text { Ref }\end{array}$ & $\begin{array}{c}0.54-2.04 \\
\text { Ref }\end{array}$ & 0.86 \\
\hline $\begin{array}{c}36.0 \text { years } \\
( \pm 8.5)\end{array}$ & $\begin{array}{c}38.2 \text { years } \\
( \pm 8.7)\end{array}$ & $\begin{array}{l}\text { Student } \\
0.034\end{array}$ & 0.97 & $0.94-1.01$ & 0.17 \\
\hline $\begin{array}{c}29(36.3 \%) \\
46(34.8 \%) \\
26(27.7 \%) \\
2\end{array}$ & $\begin{array}{c}51(63.7 \%) \\
86(65.2 \%) \\
68(72.3 \%) \\
8\end{array}$ & $\mathrm{Chi}^{2} 0.41$ & - & - & - \\
\hline $\begin{array}{c}72(37.9 \%) \\
23(29.5 \%) \\
8(16.7 \%)\end{array}$ & $\begin{array}{c}118(62.1 \%) \\
55(70.5 \%) \\
40(83.3 \%)\end{array}$ & $\mathrm{Chi}^{2} 0.016$ & $\begin{array}{l}3.24 \\
2.02 \\
\text { Ref }\end{array}$ & $\begin{array}{c}1.29-9.33 \\
0.70-6.47 \\
\text { Ref }\end{array}$ & $\begin{array}{l}0.018 \\
0.21\end{array}$ \\
\hline $\begin{array}{l}33(37.5 \%) \\
70(30.7 \%)\end{array}$ & $\begin{array}{c}55(62.5 \%) \\
158(69.3 \%)\end{array}$ & Chi $^{2} 0.25$ & - & - & - \\
\hline $\begin{array}{l}48 \text { (39.7\%) } \\
55(28.2 \%)\end{array}$ & $\begin{array}{c}73(60.3 \%) \\
140(71.8 \%)\end{array}$ & Chi $^{2} 0.035$ & $\begin{array}{l}2.33 \\
\text { Ref }\end{array}$ & $\begin{array}{c}1.20-4.65 \\
\text { Ref }\end{array}$ & 0.014 \\
\hline $\begin{array}{c}35(41.2 \%) \\
68(29.6 \%) \\
0\end{array}$ & $\begin{array}{c}50(58.8 \%) \\
162(70.4 \%) \\
1\end{array}$ & Chi $^{2} 0.051$ & - & - & - \\
\hline $\begin{array}{c}22.7 \text { years } \\
( \pm 5.9)\end{array}$ & $\begin{array}{c}23.7 \text { years } \\
( \pm 7.9)\end{array}$ & Student 0.24 & - & - & - \\
\hline $8.29( \pm 7.9)$ & $8.19( \pm 7.5)$ & Student 0.93 & 1.01 & $0.97-1.06$ & 0.51 \\
\hline $\begin{array}{c}46(32.9 \%) \\
20(27.8) \\
37(35.9 \%) \\
0\end{array}$ & $\begin{array}{c}94(67.1 \%) \\
52(72.2 \%) \\
66(64.1 \%) \\
1\end{array}$ & Chi $^{2} 0.53$ & $\begin{array}{l}0.35 \\
0.49 \\
\text { Ref }\end{array}$ & $\begin{array}{c}0.15-0.76 \\
0.22-1.05 \\
\text { Ref }\end{array}$ & $\begin{array}{c}9.0 \times 10^{-3} \\
0.072\end{array}$ \\
\hline $\begin{array}{c}57(30.8 \%) \\
44(34.9 \%) \\
2\end{array}$ & $\begin{array}{c}128(69.2 \%) \\
82(65.1 \%) \\
3\end{array}$ & $\mathrm{Chi}^{2} 0.45$ & - & - & - \\
\hline $\begin{array}{c}25(44.6 \%) \\
46(35.1 \%) \\
29(23.4 \%) \\
3\end{array}$ & $\begin{array}{c}31(55.4 \%) \\
85(64.9 \%) \\
95(76.6 \%) \\
2\end{array}$ & $\mathrm{Chi}^{2} 0.012$ & $\begin{array}{l}2.77 \\
2.12 \\
\text { Ref }\end{array}$ & $\begin{array}{c}1.10-7.03 \\
1.06-4.31 \\
\text { Ref }\end{array}$ & $\begin{array}{l}0.030 \\
0.039\end{array}$ \\
\hline $\begin{array}{c}22.3 \text { years } \\
( \pm 6.1)\end{array}$ & $\begin{array}{c}22.1 \text { years } \\
( \pm 5.5)\end{array}$ & Student 0.82 & - & - & - \\
\hline $\begin{array}{c}61(28.8 \%) \\
39(39.4 \%) \\
3\end{array}$ & $\begin{array}{c}151(71.2 \%) \\
60(60.6 \%) \\
2\end{array}$ & $\mathrm{Chi}^{2} 0.062$ & $\begin{array}{l}\text { Ref } \\
1.01\end{array}$ & $\begin{array}{c}\text { Ref } \\
0.52-1.97\end{array}$ & 0.97 \\
\hline $17.4(13.4)$ & $15.1(11.3)$ & Student 0.12 & - & - & - \\
\hline $\begin{array}{c}67(34.2 \%) \\
35(30.7 \%) \\
1\end{array}$ & $\begin{array}{c}129(65.8 \%) \\
79(69.3 \%) \\
5\end{array}$ & $\mathrm{Chi}^{2} 0.53$ & $\begin{array}{l}1.67 \\
\text { Ref }\end{array}$ & $\begin{array}{c}0.94-3.00 \\
\text { Ref }\end{array}$ & 0.083 \\
\hline
\end{tabular}

(Continued) 


\begin{tabular}{|c|c|c|c|c|c|c|}
\hline & \multicolumn{6}{|c|}{ Cocaine-Associated Chest Pain (CACP) history } \\
\hline & \multicolumn{3}{|c|}{ Univariate analysis; $n(\%) \quad(n=316)$} & \multicolumn{3}{|c|}{ Multivariate analysis $(n=282)$} \\
\hline & $\begin{array}{c}\text { CACP } \\
(n=103)\end{array}$ & $\begin{array}{l}\text { No CACP } \\
(n=213)\end{array}$ & Test $p$-value & OR & OR $95 \% \mathrm{Cl}$ & $p$-value \\
\hline \multicolumn{7}{|l|}{ Cannabis use } \\
\hline $\begin{array}{l}\text { Dependence } \\
\text { No dependence } \\
\text { Missing }\end{array}$ & $\begin{array}{c}68(35.6 \%) \\
34(28.1 \%) \\
1\end{array}$ & $\begin{array}{c}123(64.4 \%) \\
87(71.9 \%) \\
3\end{array}$ & $\mathrm{Chi}^{2} 0.17$ & - & - & - \\
\hline
\end{tabular}

a lifetime OMT prescription. Younger age was associated with a higher incidence of CACP. We did not observe a significant effect of tobacco smoking or alcohol dependence. Among the candidate genes that we tested, none reached statistical significance level, but the top SNPs were located on the GUCY1A3 and $A L D H 2$ genes.

To the best of our knowledge, this is only the second epidemiological study documenting the prevalence of lifetime CACP history in cocaine users outside of cardiologic or emergency settings, with a larger sample size to enable confirmation of descriptive results and a more powerful analysis of risk factors (11). Thus, our results confirm that both lifetime CACP history and CACP repetitive occurrence episodes are frequent. Regarding recurrences, our results are in concordance with the emergency department data (11-14).

Regarding the lifetime CACP history risk factors that we identified, namely the frequency of cocaine and amphetamine use, and the preference for rapid routes of administration, the analysis strongly suggests that both pharmacodynamic and pharmacokinetic parameters influence CACP. This is in accordance with the results of previous studies. Amphetamine use has also been described as a risk factor for chest pain or acute myocardial infarction $(7,36)$, independent of cocaine use (37). In addition to the shared acute vasoconstrictor, inotropic, chronotropic, and QT prolongation effects, amphetamine has been specifically suggested to induce chronic coronary lesions and a delayed risk of coronary events not limited to the time of amphetamine use $(36,38,39)$. Amphetamine use and frequency of use could also be a marker of severity in cocaine users. However, amphetamine use remains associated with lifetime CACP history in multivariate analysis after adjustment for cocaine use variables. Thus, our data suggest that the intensity of amphetamine and cocaine use are independent lifetime CACP history risk factors that may accumulate in an individual subject.

The negative association of OMT with lifetime CACP history observed in this study is an original result. It was observed in the multivariate analysis after adjustment for frequency and route of cocaine use and amphetamine use, underlining the importance of joint consideration in these multi-users (23). This can be explained by at least two mechanisms. First, opioids have a negative chronotropic effect and decrease the heart rate (40). This action could counteract the chronotropic effects of cocaine and reduce the oxygen requirements of the myocardium. Second, opioids have an analgesic effect and may reduce the perception of heart pain so that users would report less CACP. Although methadone and buprenorphine display different cardiovascular risk profiles (41), no difference was observed between these two drugs for lifetime CACP history in our sample. The difference in lifetime CACP history in opioid users with or without OMT prescription or between OMT drugs prescribed need to be investigated to clarify the effect of this prescription. Especially, the lack of association with opioid use without OMT prescription observed here may be the consequence of a lack of power or be the result of a specific protective effect of steady-state opioid effect of OMT rather that should not be observed with the intermittent use of street opioids.

Age is a known cardiovascular risk factor. A higher CACP history frequency and a higher number of events in younger patients seem paradoxical. First, younger patients may have severity factors that were not captured in the analysis. Second, the year of occurrence of the CACP is not recorded, and it is possible that the increase in cocaine concentration of the products traded on the illicit market or the change in adulterants over time could induce a generation effect (42). In addition, memory bias may differentially affect older patients.

Regarding tobacco smoking, there is probably a ceiling effect in this population, $94 \%$ of whom are daily tobacco smokers. In addition, lifetime alcohol dependence as recorded in our sample may have occurred concurrently or non-concurrently with the worst cocaine use period.

For candidate genetic association studies, a lack of power cannot be ruled out. Furthermore, this cohort showed the respective roles of several clinical risk factors that need to be tested independently from one another in specifically designed samples. However, our results show that clinical factors describing the intensity of psychostimulant intake have a larger effect size than individual SNPs in predicting lifetime CACP history.

Our top SNPs were intronic and located on the GUCY1A3 and $A L D H 2$ genes. For the GUCY1A3 gene, among the two identified SNPs in our results, $r s 13139571$ has been described as being associated with elevated blood pressure (43) and we could not identify any previous literature on $r 57658967$. For ALDH2 rs2238151, the CC genotype is protective against a high level of alcohol consumption and alcohol dependence (44); however, it is also a risk factor for head and neck cancers among heavy drinkers (45). This is consistent with the role of acetaldehyde metabolism in alcohol toxicity. 
This study had several limitations. First, the assessment of lifetime CACP history and other factors was carried out by a cross-sectional and retrospective interview, prone to bias. No continuous measurement of substance use has been conducted. Second, the CACP occurrences were self-declared. Thus, they were not investigated by electrocardiogram, coronarogaphy, troponin levels, or magnetic resonance imaging, to prove the cardiac origin of the chest pain (aortic dissection, crack lung, rhabdomyolysis). However, we used a rigorously standardized interview based on the anamnesis elements presented by Edmondstone (34) and excluded events not chronologically related to cocaine use. Among the 25 patients who reported having a medical consultation for CACP, the corresponding medical record was not available; especially the type of complementary examinations performed in the diagnosis process was unknown. Third, cognitive impairments were not an exclusion criterion. Mild to moderate cognitive impairments are frequent in cocaine and amphetamine users and notably in relation with the intensity of use (46), possibly leading to memory bias. Fourth, psychiatric comorbidities were not an exclusion criterion. They are associated with the prevalence of cardiovascular disease, a higher rate of cardiovascular risk factors and other risk factors shared with cocaine use, such as unhealthy lifestyle and social deprivation (47), possibly leading to a confounding bias. Fifth, our study population was composed of cocaine users currently in care. They displayed a high frequency of cocaine use, and most of them met the criteria for cocaine dependence, in addition to being multiple substance users. Our study did not cover "hidden populations," such as subjects with occasional use. Fourth Sixth, the presence of lifetime CACP history may be one of the factors motivating entry into treatment. Fifth Seventh, our retrospective interview assessed lifetime CACP events. We can only hypothesize that most of them occurred during the worst period of cocaine and amphetamine use. We only showed lifetime associations, and the causality of the identified risk factors describing cocaine and amphetamine use intensity (frequency, rapid route of administration) needs to be investigated in prospective studies. Eighth, the sample size implies a lack of power for genetic association analysis.

The strengths of our study are the use of a rigorous standardized interview to characterize CACP, and a sample size that is sufficient to provide evidence of several risk factors with acceptable power in cocaine users. Including a genetic association study is also a strength, as the results highlight the major role of the clinical factors relative to genetic factors in predicting lifetime CACP history. Lastly, our study could serve to calculate the number of subjects included in specific studies designed to test the supplementary risk conferred by the $A L D H 2$ risk genotype.

There are no validated treatments for primary prevention or recurrence. The use of beta-blockers is controversial. Long-term management includes the reduction of associated cardiovascular risk factors and abstinence of cocaine use (48). Our results suggest that harm reduction approaches may be of interest to reduce CACP occurrence, especially in patients with a previous history of CACP. This could include motivational or behavioral therapies aimed at reducing alcohol and cocaine use or changing the route of cocaine use in patients with a previous history of CACP. Optimization of OMT in patients with opioid use disorder, cocaine use disorder, and CACP history should be investigated. This could include dose optimization and diverse OMT formulation proposals, including long-term depot treatments. Future research should aim to reduce cardiac events and mortality in patients with cocaine use disorders.

\section{CONCLUSIONS}

This study confirmed that recurrent CACP events are prevalent among cocaine users. It identified lifetime CACP history risk and protective factors composed of variables describing the intensity of stimulant use and highlighted an original negative association with OMT. These factors open an avenue for targeted prevention and specific harm reduction policies targeting polydrug use and administration patterns to reduce damage associated with cardiac events. The role of OMT deserves further study.

\section{DATA AVAILABILITY STATEMENT}

The datasets presented in this article are not readily available because they are the property of the Direction de la Recherche Clinique et de l'Innovation (DRCI) of Assistance Publique Hôpitaux de Paris. Requests to access the datasets should be directed to the DRCI.

\section{ETHICS STATEMENT}

The studies involving human participants were reviewed and approved by CPP Ile de France IV. The patients/participants provided their written informed consent to participate in this study.

\section{AUTHOR CONTRIBUTIONS}

VC-D and FV drafted of manuscript. VC-D, LN-S, FV, and $\mathrm{VB}$ analyzed the data. All PSYCHOCOKE investigators have contributed to the data collection. J-LL, GB, FV, and VB wrote the protocol. All authors revised and approved the manuscript.

\section{FUNDING}

This study was funded by the French Ministry of Health (Programme Hospitalier de Recherche Clinique PHRC National 2010 AOM10165) to FV. The Délégation de la Recherche Clinique et du Développement (DRCD) from the Assistance Publique-Hôpitaux de Paris (APHP) endorsed the study. Furthermore, FV received in the past 5 years grants from the ERANET-Neuron Joint Transnational Call for European Research Projects on Synaptic dysfunction 2017 (ANR-17NEU3-0002-05), from the Labex BioPsy (Twice in 2016), a French state fund managed by the ANR within the Investissements d'Avenir program under reference ANR-11IDEX-0004-02, from the Fondation pour la Recherche en Alcoologie (Fondation de France) 2016 and 2018, from the French Ministry of Health (Programme Hospitalier de Recherche Clinique PHRC National 2018 PHRC-N-180777), and from the 
FHU NOR-SUD (INSERM/APHP/Université de Paris) internal call (2020). VC-D received a grant from the FHU NOR-SUD (INSERM/APHP/Université de Paris) internal call (2020). FB was the Principal Investigator on the R-LiNK (Response to Lithium Network) project. This project has received funding from the European Union Horizon 2020 research and innovation program (EU.3.1.1. Understanding health, wellbeing and disease: Grant No. 754907). AM was supported by the Netherlands Organization for Research (NWO) Vidi grant 0.16.Vidi.185.044.

\section{ACKNOWLEDGMENTS}

The authors thank the professional English proofreading services of Taylor and Francis Editing Services.

\section{REFERENCES}

1. United Nations Office on Drugs and Crime. Division for Policy Analysis and Public Affairs. World Drug Report 2019. (2019). Vienna. Available online at: https://wdr.unodc.org/wdr2019/ (accessed July 1, 2021).

2. Substance Abuse and Mental Health Services Administration. Key Substance Use and Mental Health Indicators in the United States: Results From the 2018 National Survey on Drug Use and Health. Rockville, MD: Center for Behavioral Health Statistics and Quality, Substance Abuse and Mental Health Services Administration (2019). Available online at: https://www.samhsa.gov/ data/sites/default/files/cbhsq-reports/NSDUHNationalFindingsReport2018/ NSDUHNationalFindingsReport2018.pdf (accessed July 1, 2021).

3. European Monitoring Centre for Drugs and Drug Addiction. European Drug Report 2019: Trend and Developments. Lisbon: Office for Official Publications of the European Communities (2019). Available online at: https://www.emcdda.europa.eu/system/files/publications/11364/ 20191724_TDAT19001ENN_PDF.pdf (accessed July 1, 2021).

4. Milpied T, Clergue-Duval V, Vorspan F. Épidémiologie des substances illicites en France [Epidemiology of illicit substances in France]. Rev Prat. (2020) 70:657-9.

5. Lange RA, Hillis LD. Cardiovascular complications of cocaine use. N. Engl J Med. (2001) 345:351-8. doi: 10.1056/NEJM200108023450507

6. Havakuk O, Rezkalla SH, Kloner RA. The cardiovascular effects of cocaine. J Am Coll Cardiol. (2017) 70:101-13. doi: 10.1016/j.jacc.2017.05.014

7. Duflou J. Psychostimulant use disorder and the heart. Addiction. (2020) 115:175-83. doi: 10.1111/add.14713

8. Winhusen T, Theobald J, Kaelber DC, Lewis D. The association between regular cocaine use, with and without tobacco co-use, and adverse cardiovascular and respiratory outcomes. Drug Alcohol Depend. (2020) 214:108136. doi: 10.1016/j.drugalcdep.2020.108136

9. Mir,ó Ò, Dargan PI, Wood DM, Dines AM, Yates C, Heyerdahl F, et al. Epidemiology, clinical features and management of patients presenting to European emergency departments with acute cocaine toxicity: comparison between powder cocaine and crack cocaine cases. Clin Toxicol. (2019) 57:71826. doi: 10.1080/15563650.2018.1549735

10. Carrillo X, Curós A, Muga R, Serra J, Sanvisens A, Bayes-Genis A. Acute coronary syndrome and cocaine use: 8 -year prevalence and inhospital outcomes. Eur Heart J. (2011) 32:1244-50. doi: 10.1093/eurheartj/ehq504

11. Delchev Y, Fortias M, Dupuy G, Orizet C, Bloch V, Puymirat E, et al. Transient cocaine-induced chest pain: a case series. J Addict Med. (2014) 8:111-5. doi: 10.1097/ADM.0000000000000016

12. Cunningham R, Walton MA, Weber JE, O’Broin S, Tripathi SP, Maio RF, et al. One-year medical outcomes and emergency department recidivism after emergency department observation for cocaine-associated chest pain. Ann Emerg Med. (2009) 53:310-20. doi: 10.1016/j.annemergmed.2008.07.018

13. Hollander JE, Hoffman RS, Gennis P, Fairweather P, DiSano MJ, Schumb DA, et al. Prospective multicenter evaluation of cocaine-associated chest pain.

\section{THE PSYCHOCOKE INVESTIGATORS}

Florence Vorspan, Maeva Fortias, Jean-Pierre Lépine, Georges Brousse, Ingrid de Chazeron, El-Hadi Zerdazi, Jean-Baptiste Trabut, Beatriz Belforte, Philippe Coeuru, Delphine Moisan, Arnaud Plat, Philippe Batel, Alice Deschenau, Olivier Cottencin, Aurelia Gay, Philippe Lack and Anne-Laure Pelissier-Alicot.

\section{SUPPLEMENTARY MATERIAL}

The Supplementary Material for this article can be found online at: https://www.frontiersin.org/articles/10.3389/fpsyt. 2021.704276/full\#supplementary-material

Cocaine Associated Chest Pain (COCHPA) Study Group. Acad Emerg Med. (1994) 1:330-9. doi: 10.1111/j.1553-2712.1994.tb02639.x

14. Weber JE, Chudnofsky CR, Boczar M, Boyer EW, Wilkerson MD, Hollander JE. Cocaine-associated chest pain how common is myocardial infarction? Acad Emerg Med. (2000) 7:873-7. doi: 10.1111/j.1553-2712.2000.tb02064.x

15. Gitter MJ, Goldsmith SR, Dunbar DN, Sharkey SW. Cocaine and chest pain: clinical features and outcome of patients hospitalized to rule out myocardial infarction. Ann Intern Med. (1991) 115:277-82. doi: 10.7326/0003-4819-115-4-277

16. Amsterdam EA, Kirk JD, Bluemke DA, Diercks D, Farkouh ME, Garvey JL, et al. Testing of low-risk patients presenting to the emergency department with chest pain: a scientific statement from the American Heart Association. Circulation. (2010) 122:1756-76. doi: 10.1161/CIR.0b013e3181ec61df

17. Guirgis FW, Gray-Eurom K, Mayfield TL, Imbt DM, Kalynych CJ, Kraemer DF, et al. Impact of an abbreviated cardiac enzyme protocol to aid rapid discharge of patients with cocaine-associated chest pain in the clinical decision unit. West J Emerg Med. (2014) 15:180-3. doi: 10.5811/westjem.2013.11.19232

18. Finkel JB, Marhefka GD. Rethinking cocaine-associated chest pain and acute coronary syndromes. Mayo Clin Proc. (2011) 86:1198-207. doi: $10.4065 / \mathrm{mcp} .2011 .0338$

19. Bachi K, Mani V, Jeyachandran D, Fayad ZA, Goldstein RZ, Alia-Klein N. Vascular disease in cocaine addiction. Atherosclerosis. (2017) 262:15462. doi: 10.1016/j.atherosclerosis.2017.03.019

20. Pennings EJM, Leccese AP, de Wolff FA. Effects of concurrent use of alcohol and cocaine: concurrent use of alcohol and cocaine. Addiction. (2002) 97:77383. doi: $10.1046 / j .1360-0443.2002 .00158 . x$

21. Andrews P. Cocaethylene toxicity. J Addict Dis. (1997) 16:7584. doi: 10.1300/J069v16n03_08

22. da Maia AFS, Martins FT, da Silva Neto L, Alves RB, De Fátima Â. Cocaethylene, the in vivo product of cocaine and ethanol, is a narcotic more potent than its precursors. Acta Crystallogr Section C Struct Chem. (2017) 73:780-3. doi: $10.1107 /$ S2053229617012852

23. Karsinti E, Piani K, Zerdazi EH, Maskos U, Faure P, Romo L, et al. Relevance of treated cocaine users' retrospective memory of first cocaine use. Psychiatry Res. (2018) 264:210-6. doi: 10.1016/j.psychres.2018.03.058

24. Böhm F, Pernow J. The importance of endothelin-1 for vascular dysfunction in cardiovascular disease. Cardiovasc Res. (2007) 76:8-18. doi: 10.1016/j.cardiores.2007.06.004

25. Farah C, Michel LYM, Balligand, J.-L. Nitric oxide signalling in cardiovascular health and disease. Nat Rev Cardiol. (2018) 15:292-316. doi: 10.1038/nrcardio.2017.224

26. Strassheim D, Gerasimovskaya E, Irwin D, Dempsey EC, Stenmark K, Karoor V. RhoGTPase in vascular disease. Cells. (2019) 8:551. doi: $10.3390 /$ cells 8060551

27. Wobst J, Schunkert H, Kessler T. Genetic alterations in the NOcGMP pathway and cardiovascular risk. Nitric Oxide. (2018) 76:10512. doi: $10.1016 /$ j.niox.2018.03.019 
28. Pradhan L, Mondal D, Chandra S, Ali M, Agrawal KC. Molecular analysis of cocaine-induced endothelial dysfunction: role of endothelin-1 and nitric oxide. Cardiovasc Toxicol. (2008) 8:161-71. doi: 10.1007/s12012-0089025-Z

29. Yasue H, Mizuno Y, Harada E. Coronary artery spasm - clinical features, pathogenesis and treatment. Proc Jpn Acad Series B. (2019) 95:5366. doi: 10.2183/pjab.95.005

30. Bosron WF, Li TK. Genetic polymorphism of human liver alcohol and aldehyde dehydrogenases, and their relationship to alcohol metabolism and alcoholism. Hepatology. (1986) 6:502-10. doi: 10.1002/hep.1840060330

31. Xu K, Kranzler HR, Sherva R, Sartor CE, Almasy L, Koesterer R, et al. Genomewide association study for maximum number of alcoholic drinks in European Americans and African Americans. Alcohol Clin Exp Res. (2015) 39:1137-47. doi: 10.1111/acer.12751

32. Yang M, Zhang Y, Ren J. ALDH2 Polymorphism and ethanol consumption: a genetic-environmental interaction in carcinogenesis. In: Ren J, Zhang Y, Ge J, editors. Aldehyde Dehydrogenases. Singapore: Springer Singapore (2019). p. 229-36.

33. Marees AT, de Kluiver H, Stringer S, Vorspan F, Curis E, Marie-Claire $\mathrm{C}$, et al. A tutorial on conducting genome-wide association studies: quality control and statistical analysis. Int J Methods Psychiatr Res. (2018) 27:e1608. doi: 10.1002/mpr.1608

34. Edmondstone WM. Cardiac chest pain: does body language help the diagnosis? BMJ. (1995) 311:1660-61. doi: 10.1136/bmj.311.7021.1660

35. American Psychiatric Association. Diagnostic and Statistical Manual of Mental Disorders. 4th ed., text rev. Washington, DC: American Psychiatric Association (2000).

36. Kaye S, McKetin R, Duflou J, Darke S. Methamphetamine and cardiovascular pathology: a review of the evidence. Addiction. (2007) 102:1204-11. doi: 10.1111/j.1360-0443.2007.01874.x

37. Westover AN, Nakonezny PA, Haley RW. Acute myocardial infarction in young adults who abuse amphetamines. Drug Alcohol Depend. (2008) 96:4956. doi: 10.1016/j.drugalcdep.2008.01.027

38. Karch SB, Stephens BG, Ho CH. Methamphetamine-related deaths in San Francisco: demographic, pathologic, and toxicologic profiles. J Forensic Sci. (1999) 44:359-68. doi: 10.1520/JFS14464J

39. Darke S, Duflou J, Kaye S. Prevalence and nature of cardiovascular disease in methamphetamine-related death: a national study. Drug Alcohol Depend. (2017) 179:174-9. doi: 10.1016/j.drugalcdep.2017.07.001

40. Pugsley MK. The diverse molecular mechanisms responsible for the actions of opioids on the cardiovascular system. Pharmacol Ther. (2002) 93:5175. doi: 10.1016/S0163-7258(02)00165-1

41. Krantz MJ, Palmer RB, Haigney MCP. Cardiovascular complications of opioid use: JACC state-of-the-art review. J Am Coll Cardiol. (2021) 77:20523. doi: 10.1016/j.jacc.2020.11.002
42. Detrez V. Le Point SINTES $n^{\circ}$ 6. Paris: Observatoire Français des Drogues et des Toxicomanies (2020). Available online at: www.ofdt.fr/BDD/sintes/LePointSINTES06.pdf (accessed March 31, 2021).

43. The International Consortium for Blood Pressure Genome-Wide Association Studies. Genetic variants in novel pathways influence blood pressure and cardiovascular disease risk. Nature. (2011) 478:103-9. doi: 10.1038/nature10405

44. Macgregor S, Lind PA, Bucholz KK, Hansell NK, Madden PAF, Richter MM, et al. Associations of $\mathrm{ADH}$ and $\mathrm{ALDH} 2$ gene variation with self report alcohol reactions, consumption and dependence: an integrated analysis. $\mathrm{Hum} \mathrm{Mol}$ Genet. (2009) 18:580-93. doi: 10.1093/hmg/ddn372

45. Hakenewerth AM, Millikan RC, Rusyn I, Herring AH, North KE, BarnholtzSloan JS, et al. Joint effects of alcohol consumption and polymorphisms in alcohol and oxidative stress metabolism genes on risk of head and neck cancer. Cancer Epidemiol Biomark Prevent. (2011) 20:243849. doi: 10.1158/1055-9965.EPI-11-0649

46. Lappin JM, Sara GE. Psychostimulant use and the brain. Addiction. (2019) 114:2065-77. doi: 10.1111/add.14708

47. Nielsen RE, Banner J, Jensen SE. Cardiovascular disease in patients with severe mental illness. Nat Rev Cardiol. (2021) 18:136-45. doi: 10.1038/s41569-020-00463-7

48. McCord J, Jneid H, Hollander JE, de Lemos JA, Cercek B, Hsue P, et al. Management of cocaine-associated chest pain and myocardial infarction: a scientific statement from the American Heart Association Acute Cardiac Care Committee of the Council on Clinical Cardiology. Circulation. (2008) 117:1897-907. doi: 10.1161/CIRCULATIONAHA.107.188950

Conflict of Interest: In the past 5 years, FV had congress fees paid by CAMURUS $\mathrm{AB}$ (2018, 2019), and RECORDATI (2020). FV gave a single lecture for RECORDATI (2020) and served in advisory boards for CAMURUS AB (2019), and ACCORD HEALTH CARE (2021). All payments were made to a research entity and not directly to FV.

The remaining authors declare that the research was conducted in the absence of any commercial or financial relationships that could be construed as a potential conflict of interest.

Copyright (c) 2021 Clergue-Duval, Nicolas-Sacy, Karsinti, Zerdazi, Laplanche, Brousse, Marees, Derks, Henry, Bellivier, Vorspan and Bloch. This is an open-access article distributed under the terms of the Creative Commons Attribution License (CC $B Y)$. The use, distribution or reproduction in other forums is permitted, provided the original author(s) and the copyright owner(s) are credited and that the original publication in this journal is cited, in accordance with accepted academic practice. No use, distribution or reproduction is permitted which does not comply with these terms. 